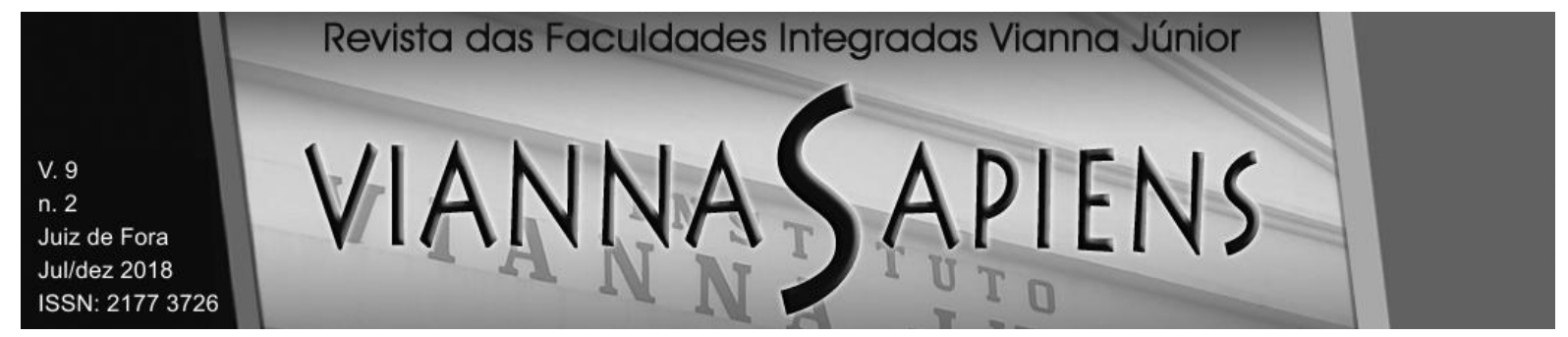

\title{
IDENTIFICAÇÃO DE FATORES QUE INFLUENCIAM A INTENÇÃO DE USO DE COMENTÁRIOS DE VIAGEM ON-LINE PARA ESCOLHA DE UM MEIO DE HOSPEDAGEM
}

DOI: 10.31994/rvs.v9i2.377

\author{
Antônio Sérgio Bolonha Ferreira ${ }^{1}$ \\ Artur Luiz Santana Moreira ${ }^{2}$ \\ Gédison Peixoto de Oliveira Junior ${ }^{3}$ \\ Paulo Roberto da Costa Vieira ${ }^{4}$
}

\section{RESUMO}

O presente trabalho teve o propósito de analisar os fatores que influenciam a intenção de uso de Comentários de Viagens On-line (CVO) na escolha de um meio de hospedagem. Para tal, foi realizada pesquisa survey, com amostra de conveniência constituída por 232 respondentes nas cidades do Rio de Janeiro e de Cabo Frio. Empregou-se o questionário estruturado, com opções de resposta Likert, para coleta de dados. O tratamento de dados foi realizado por intermédio da Modelagem de Equações Estruturais, com base em mínimos quadrados parciais. $O$ modelo conceitual de pesquisa foi baseado no Modelo de Aceitação Tecnológica (MAT) e na Teoria Motivacional. Os resultados confirmaram que a intenção do usuário de usar CVO sofre impacto estatisticamente significativo da utilidade

\footnotetext{
${ }^{1}$ Mestrando em Administração e Desenvolvimento Empresarial pela Universidade Estácio de Sá, UNESA - Brasil; email sergiobolonha@gmail.com; https://orcid.org/0000-0001-7531-4141

2 Doutor em Administração pelo Instituto Coppead da Universidade Federal do Rio de Janeiro, UFRJ - Brasil; email artur.moreira@estacio.br; https://orcid.org/0000-0002-9201-1377

${ }^{3}$ Mestrando em administração e desenvolvimento empresarial pela Universidade Estácio de Sá, UNESA - Brasil; email gedisonpeixoto@hotmail.com; https://orcid.org/0000-0001-9891-2478

${ }^{4}$ Doutor em Administração pelo Instituto Coppead da Universidade Federal do Rio de Janeiro, UFRJ - Brasil; email paulo.vieira@estacio.br; https://orcid.org/0000-0003-3742-1127
} 


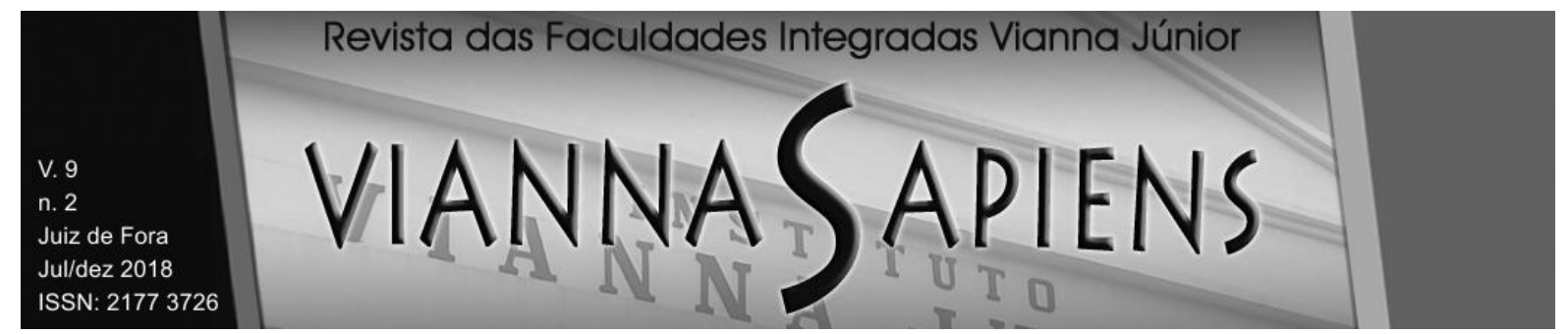

percebida, da facilidade percebida, da atitude percebida e do prazer percebido.

PALAVRAS-CHAVE: COMENTÁRIOS DE VIAGEM ON-LINE. MODELO DE ACEITAÇÃO TECNOLÓGICA. TEORIA MOTIVACIONAL. MEIO DE HOSPEDAGEM. TURISMO.

\title{
IDENTIFYING FACTORS INFLUENCING THE INTENTION TO USE ON-LINE TRAVEL REVIEWS TO CHOOSE A HOSTING MEDIUM
}

\begin{abstract}
This study aimed to evaluate the factors that influence the use of Online Travel Reviews (CVO) in the choice of a hosting environment. For that, a survey was carried out, with response analysis of 232 respondents in the cities of Rio de Janeiro and Cabo Frio. The structured questionnaire, with Likert response options, it was employed for data collection. The data treatment was done through the Structural Equation Modeling, based on the partial least squares. The research model was based on the Technological Acceptance Model (TAM) and Motivational Theory. The results were confirmed, and the user's intention to use CVO was significantly impacted by the perceived utility, perceived ease, perceived attitude, and perceived pleasure.
\end{abstract}

KEYWORDS: ONLINE TRAVEL REVIEWS. TECHNOLOGICAL ACCEPTANCE MODEL. MOTIVATIONAL THEORY. LODGING. TOURISM. 


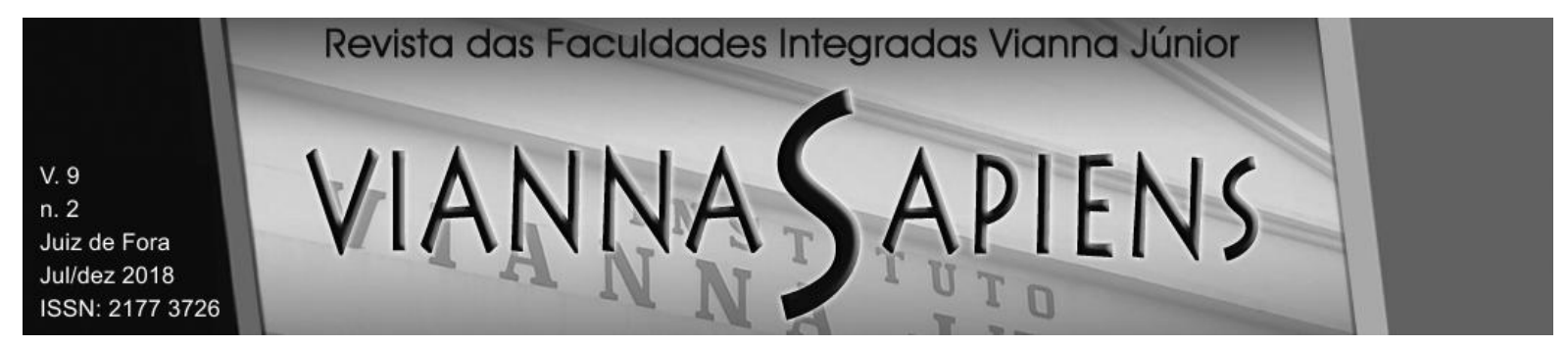

\section{INTRODUÇÃO}

A internet permitiu, entre infinitas possibilidades, que os consumidores com intenção de viajar tivessem acesso às informações de inúmeros meios de hospedagem, de diversas categorias, espalhados geograficamente pelo globo. De hotel de luxo a pousada, de casa de praia a apartamento localizado em um centro financeiro, seja em localidade remota no Caribe seja em megalópole norteamericana, existem opções que certamente estarão de acordo com o perfil desejado pelo viajante. Isso possibilitou que os meios de hospedagem fossem selecionados, em período relativamente curto de tempo, pelo público interessado, segundo seu perfil e sua restrição orçamentária.

Impulsionados pelas facilidades proporcionadas pela tecnologia e pela disseminação das redes sociais, surgiram sites com conteúdo composto por relatos e fotos de viajantes. Do mesmo modo, foram criados sites de reserva em meios de hospedagem, sendo que diversos hotéis e pousadas passaram a oferecer espaço para sugestões e opiniões dos turistas, gerando, todos eles, meios para repercutir 0 boca-a-boca entre clientes viajantes e em redes de relacionamento na internet, com a acessibilidade aumentada pela disseminação dos dispositivos móveis (MAURI; MINAZZI, 2013).

Os turistas que planejam viagens procuram esses Comentários de Viagens On-line (CVO) para obter informações que possibilitem alinhar seus planos de viagens às percepções passadas pelos viajantes sobre os locais visitados, demonstrando que consideram esse tipo de comentários confiáveis e úteis (AYEH; AU; LAW, 2013; SPARKS; PERKINS; BUCKLEY, 2013).

Há estudos que demonstram a influência dos comentários feitos por viajantes em sites relacionados a turismo sobre a venda de quartos em hotéis, viagens e hospedagem (YE; LAW; GU, 2009; CORTEZ; MONDO, 2018).

Este estudo busca identificar os fatores que influenciam a intenção de uso de CVO na escolha de um meio de hospedagem, utilizando a Modelo de Aceitação 


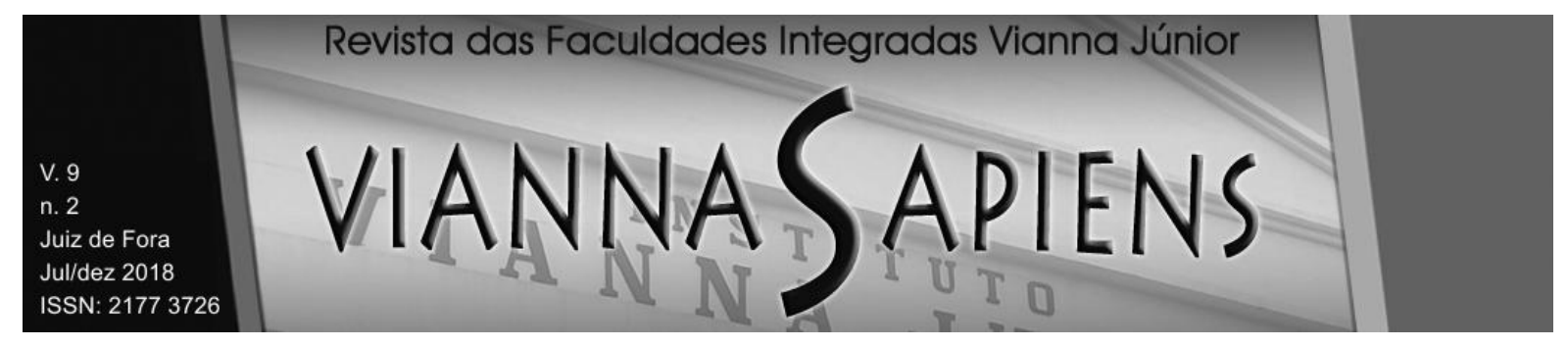

Tecnológica (DAVIS, 1989) e a Teoria Motivacional (DAVIS; BAGOZZI; WARSHAW, 1992) como bases teóricas.

O presente trabalho foi inspirado no modelo desenvolvido por Silva e Mendes Filho (2014) para analisar os fatores que influenciam a intenção de uso de CVO na escolha de um meio de hospedagem. Esse modelo supõe a existência de nexo causal entre os construtos exógenos (atitude percebida; utilidade percebida; prazer percebido; e facilidade percebida) e o endógeno (intenção de uso) (Figura 1).

O modelo utilizado neste trabalho contempla as seguintes hipóteses: 1) a utilidade percebida de uso de CVO influencia positivamente a atitude em utilizá-lo na escolha de um meio de hospedagem (primeira hipótese); 2) a utilidade percebida de uso de CVO influencia positivamente a intenção de utilizá-lo na escolha de um meio de hospedagem (segunda hipótese); 3) a facilidade percebida no uso de CVO influencia positivamente utilidade percebida na escolha de um meio de hospedagem (terceira hipótese); 4) a facilidade percebida no uso de CVO influencia positivamente atitude em utilizá-lo na escola de um meio de hospedagem (quarta hipótese); 5) a atitude em usar CVO influencia positivamente a intenção de utilizá-lo na escolha de um meio de hospedagem (quinta hipótese); 6) o prazer percebido influencia positivamente a facilidade percebida de usar CVO na escolha de um meio de hospedagem (sexta hipótese); 7) o prazer percebido influencia positivamente a atitude de usar CVO na escolha de um meio de hospedagem (sétima hipótese); e 8) o prazer percebido influencia positivamente a intenção de usar CVO na escolha de um meio de hospedagem (oitava hipótese) (SILVA; MENDES FILHO, 2014). 

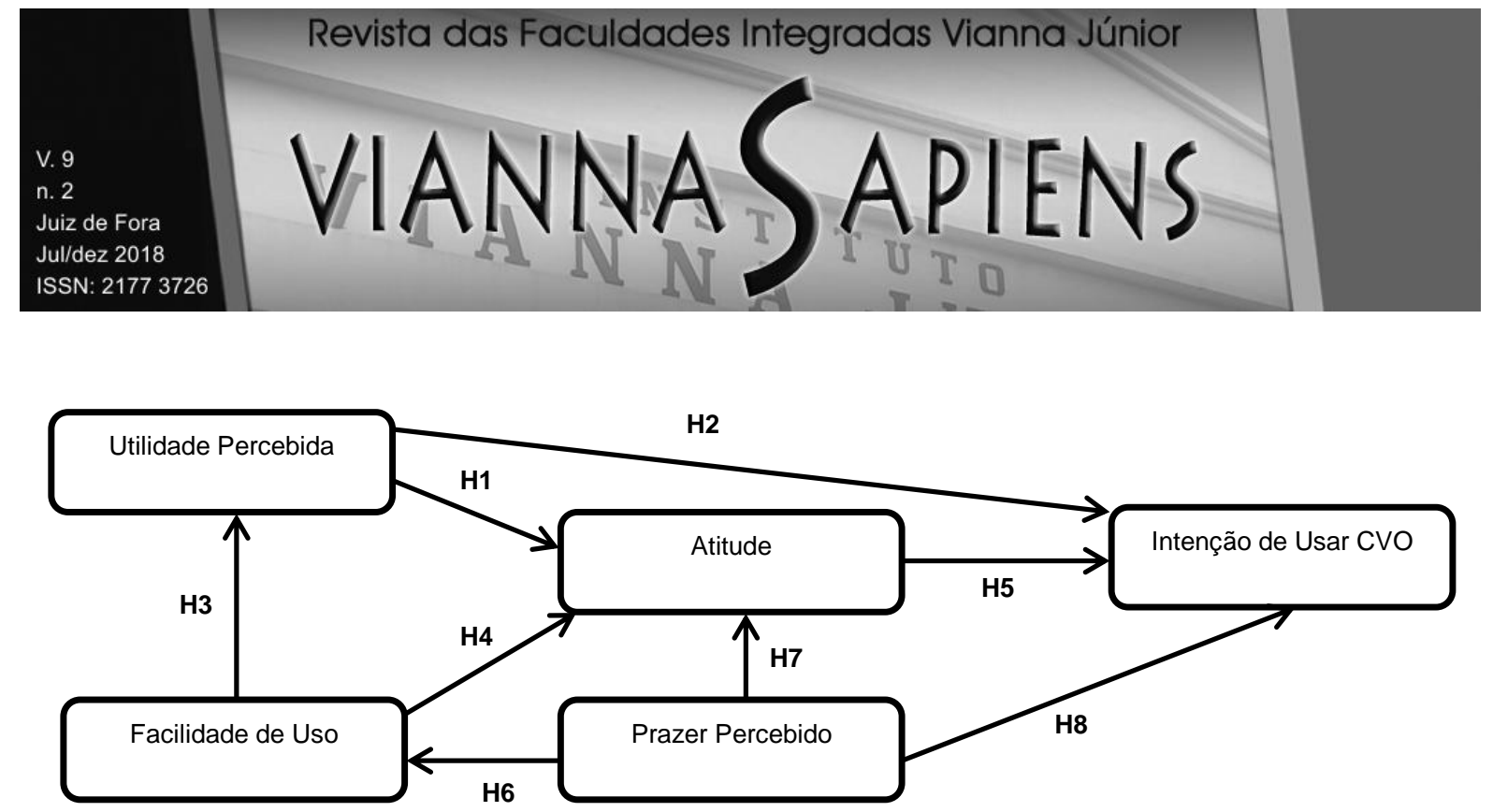

Figura 1 - Modelo de Pesquisa

Fonte: Adaptado de Silva e Mendes Filho (2014)

\section{REFERENCIAL TEÓRICO}

O objeto do presente estudo são os CVO e sua influência no que tange à escolha de um meio de hospedagem por viajantes que estão em fase de planejamento ou de efetivação de seus roteiros de viagem. Nas seções subsequentes, será realizada a revisão de literatura, com discussão das teorias que fundamentaram o modelo hipotético deste estudo.

\subsection{Comentários de Viagem On-line (CVO)}

O fato de o turismo ser intangível e heterogêneo criou a necessidade de os clientes de hotel serem atendidos nas suas expectativas ao comprar a experiência de hospedagem, devendo os hotéis proverem informações que descrevam os produtos dos hotéis, já que o cliente não pode testar a aquisição (MOROSAN; BOWEN, 2017; MENDES FILHO; JORGE; SENA JÚNIOR, 2014).

Independentemente do conteúdo fornecido pelos hotéis, os turistas compartilham suas experiências de viagem com outras pessoas por meio de CVO (SCHUCKERT; XIANWEI; LAW, 2015). 


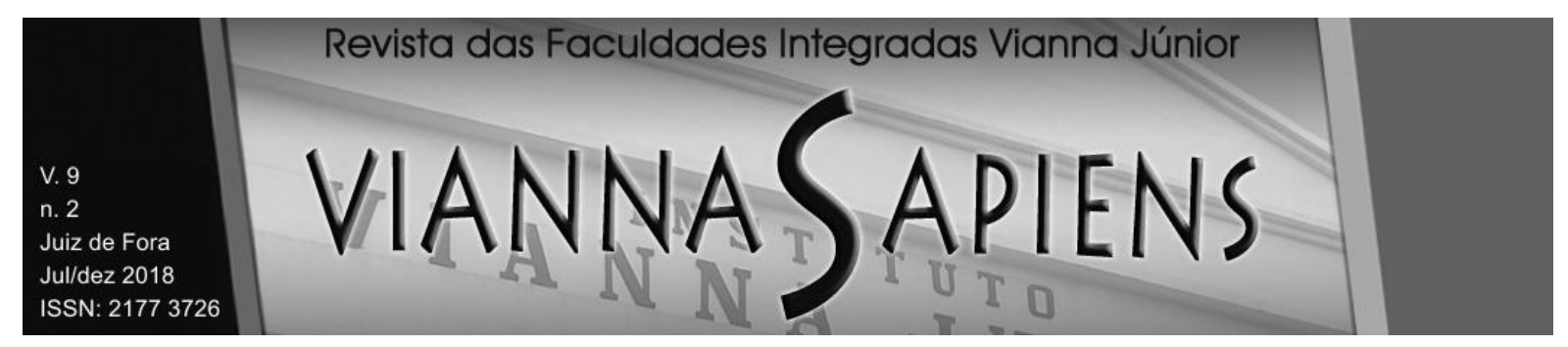

Os consumidores muitas vezes tentam ter uma ideia de como será um destino ou um estabelecimento de hospedagem antes da sua viagem, e, por esse motivo, procuram comentários de viajantes que deixaram sua opinião on-line (FILIERI; ALGUEZAUI; MCLEAY, 2015).

Segundo Silva e Mendes Filho (2014), a prática de CVO vem contribuindo para a difusão do boca-a-boca on-line, que, similarmente à propaganda boca a boca, é a divulgação positiva ou negativa feita por clientes, sejam antigos, atuais ou potenciais, a respeito de um produto, serviço ou empresa, por meio de canais apoiados na internet (HENNIG-THURAU; GWINNER; WALSH; GREMLER, 2004; SANTOS, CHAVES; PEDRON, 2014).

O boca-a-boca on-line, pelo imediatismo da disponibilidade da informação, que pode ser colocada mesmo durante a experiência do consumidor, proporciona impactos maiores, devido à rapidez e alcance da internet (SANTOS; CHAVES; PEDRON, 2014), e está se tornando uma das principais fontes de informação para os turistas (AYEH; AU; LAW, 2013).

Quanto mais os consumidores percebem que um conteúdo colocado por usuário é confiável, mas estão dispostos a conversar com seus amigos sobre isso (FILIERI; ALGUEZAUI; MCLEAY, 2015).

A busca de informações em CVO impacta sobremaneira na reputação da marca do hotel, uma vez que o conteúdo da marca na web não é mais controlado pelas empresas e organizações, mas é de domínio das interações e participações de usuários ativos na criação de conteúdo on-line, devendo o hotel dar a devida atenção às mídias digitais para fidelizar consumidores (O'CONNOR, 2008 apud SILVA; MENDES FILHO, 2014; SANTOS; CHAVES; PEDRON, 2014).

Os comentários de viagem on-line (CVO) configuram comportamento voluntário dos clientes, fornecendo informações espontâneas para auxiliar o processo de tomada de decisão de outros viajantes, o que incentiva os gerentes de hospedagem a melhorar a qualidade do serviço (SCHUCKERT; XIANWEI; LAW, 2015). 


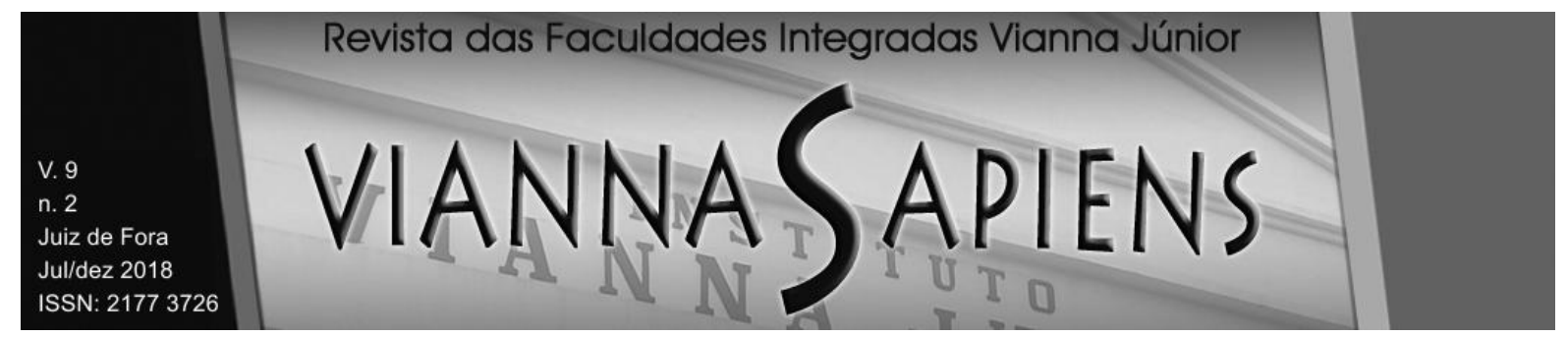

\subsection{Modelo de Aceitação Tecnológica (MAT)}

O Modelo de Aceitação Tecnológica (MAT) (DAVIS, 1989) foi adaptado da Teoria da Ação Racional (TAR) (AYEH; AU; LAW, 2013). A TAR explica que determinado comportamento é influenciado pela atitude, a qual é determinada por normas subjetivas em relação ao comportamento em questão (AYEH; AU; LAW, 2013). O MAT considera que a utilidade percebida e a facilidade de uso percebida são variáveis determinantes para aceitação de tecnologia pelo usuário, sendo que a facilidade de uso percebida pode ser um antecedente causal da utilidade percebida (DAVIS, 1989). O MAT é frequentemente usado para explicar a aceitação de novas tecnologias da informação e suas aplicações (SILVA; MENDES FILHO, 2014; LAI, 2017) - ver Figura 2.

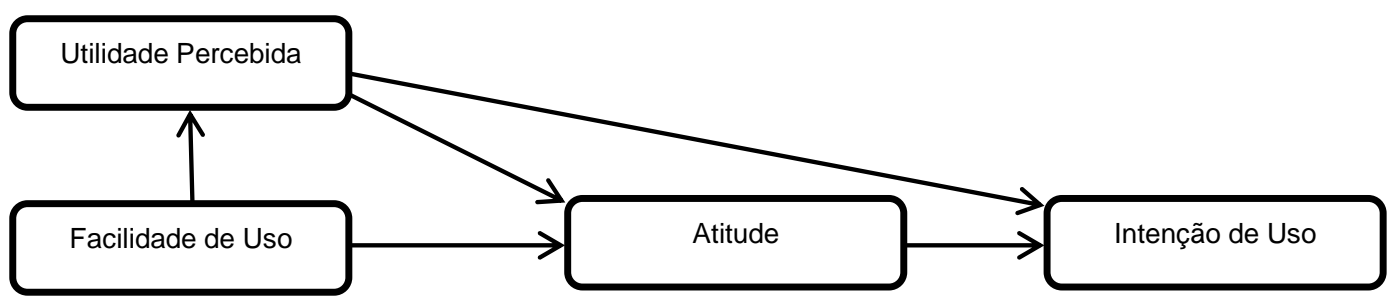

Figura 2 - Modelo de Aceitação Tecnológica

Fonte: Adaptado de Davis (1989), apud Silva e Mendes Filho (2014)

Para Davis (1989), a utilidade percebida é o quanto o usuário subjetivamente acredita que a tecnologia em questão é útil para melhorar o desempenho de suas tarefas. Da mesma forma, a facilidade de uso refere-se ao quanto o usuário entende que o uso da tecnologia é livre de esforço.

Conforme mostra a Figura 2, cujas setas representam as relações causais entre os construtos, a utilidade percebida e a facilidade de uso influenciam a atitude, a qual exerce impacto sobre a intenção do usuário no tocante ao uso da tecnologia (DAVIS, 1989; CASALÓ, FLAVIÁN; GUINALÍU, 2011; SILVA; MENDES FILHO, 2014). 


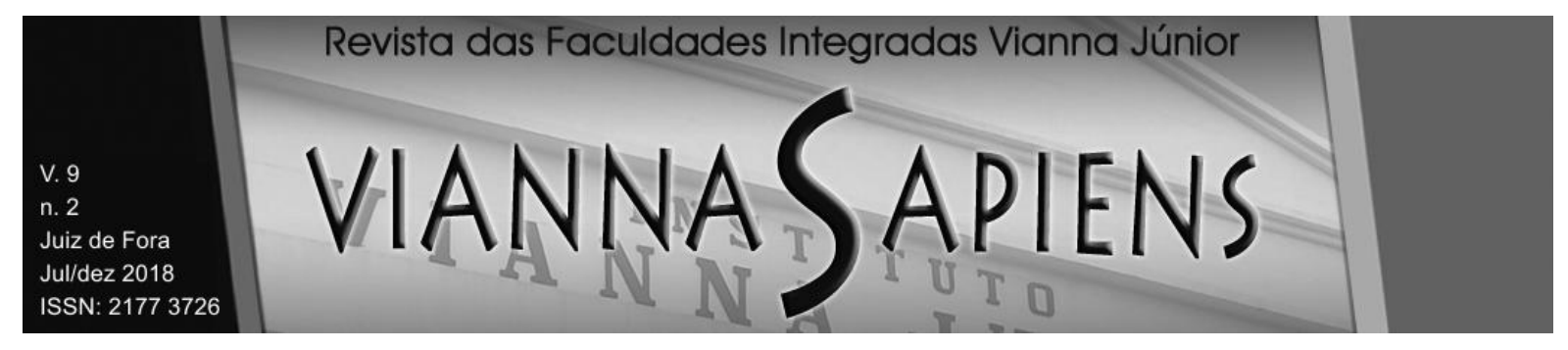

O cenário atual, no que se refere à evolução e à oferta de tecnologia, é diferente do contexto da proposição do MAT, mas seus fundamentos continuam válidos, mesmo se aplicados em um conceito mais amplo de tecnologia (GOUVÊA; SÁ; MANTOVANI, 2012). Adicionalmente, há estudos que oferecem suporte empírico ao uso do MAT na utilização da tecnologia em empreendimentos turísticos e hotelaria (CASTAÑEDA et al., 2007; HUH; KIM; LAW, 2009).

\subsection{Teoria Motivacional}

A Teoria Motivacional, proposta por Davis, Bagozzi e Warshaw (1992), define que o comportamento dos usuários de internet pode variar dependendo de sua motivação extrínseca ou intrínseca (SILVA; MENDES FILHO, 2014). Os viajantes podem usar sites de comentários por motivação extrínseca, ou seja, causada por fatores externos para obter recompensas específicas, como fazer planejamento de viagens, ou por motivação intrínseca, isto é, causada por fatores internos, como a satisfação que tem ao realizar a busca. (AYEH; AU; LAW, 2013).

Davis, Bagozzi e Warshaw (1992) demonstram que, ao usar sistemas percebidos como de pouca utilidade, o prazer percebido tem pouca influência na aceitação da tecnologia pelos usuários, mas quando, ao contrário, são entendidos como de grande utilidade, o prazer percebido aumenta a aceitação do sistema. No mesmo estudo, observam que a aplicação de tecnologia precisa endereçar tarefas que os usuários considerem importantes, pois, sem isso, mesmo que o sistema seja fácil de usar, não haverá motivação para tanto.

Castañeda et al. (2007), em estudo no qual o prazer percebido é trabalhado como fator interno de motivação, argumentam que a motivação intrínseca pode prevalecer sobre a motivação extrínseca em casos de procura por informações de viagem. Se a motivação intrínseca for alta, os usuários tendem a investir mais tempo realizando determinada tarefa, o que resulta em percepção de facilidade de uso. Ryan e Deci (2001) afirmam que a níveis mais altos de motivação intrínseca os 


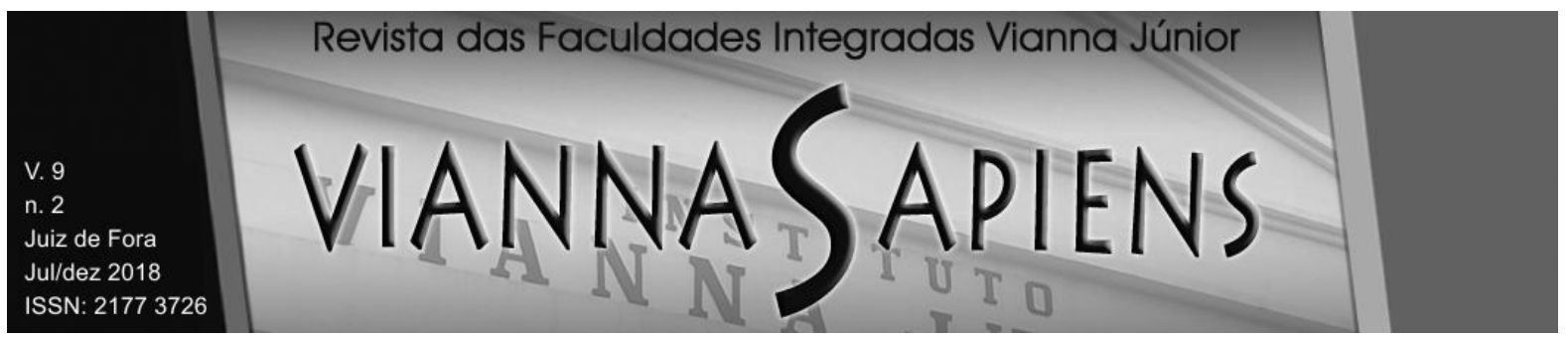

indivíduos tendem a gastar mais tempo em uma dada tarefa, e, como resultado, desenvolvem a percepção de facilidade de uso, como ficou evidenciado no estudo de Silva e Mendes Filho (2014).

\section{MÉTODO}

A presente pesquisa é de natureza quantitativa, com enfoque explicativo, já que considera relações causais entre as variáveis latentes do modelo. Com o objetivo de obter um número expressivo de informações por respondente, empregou-se a pesquisa de survey.

\subsection{População e Amostra}

A população desta pesquisa é composta por usuários de comentários on-line na escolha de meios de hospedagem. A amostra foi do tipo não probabilístico, escolhida por conveniência, composta por 232 respondentes nas cidades do Rio de Janeiro e de Cabo Frio, na sua grande maioria estudantes de universidades públicas e privadas.

\subsection{Coleta dos Dados}

Os dados foram coletados por meio de questionário estruturado e auto administrado, com escala Likert de sete opções de resposta, baseado no modelo desenvolvido por Silva (2015). Cada item do questionário corresponde a um indicador (variável observada) do modelo de mensuração associado ao modelo hipotético. O quadro 1 exibe esses indicadores (variáveis observadas), os quais foram agrupados por variáveis latentes (construtos) do modelo hipotético de 


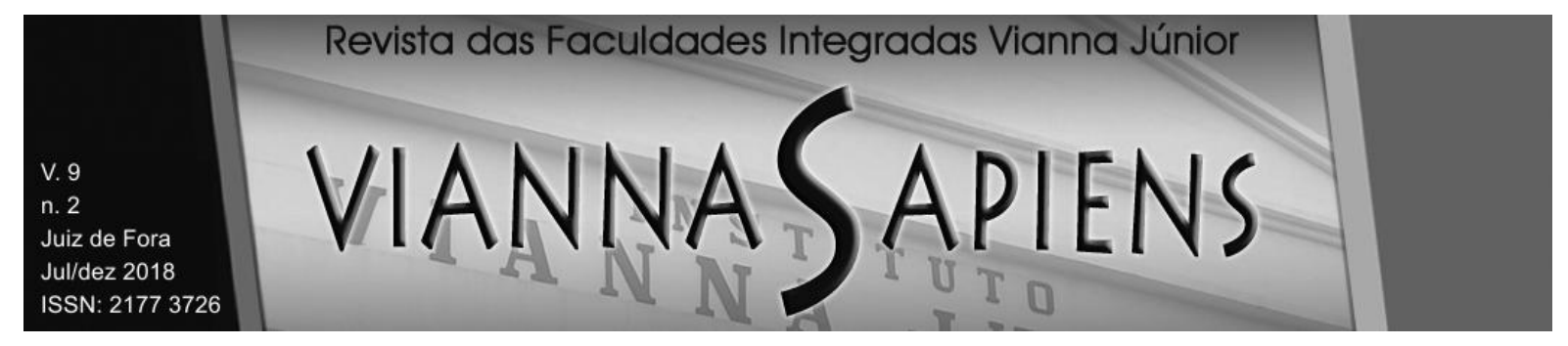

intenção de uso de comentários de viagem on-line, para escolha de um meio de hospedagem.

\section{Quadro 1 - Itens do questionário relacionados às variáveis do modelo}

\begin{tabular}{|c|c|c|c|}
\hline Variável/ Fator & Indicador & Item & Autor \\
\hline \multirow{4}{*}{ Atitude } & AT1 & $\begin{array}{l}\text { É uma boa ideia usar CVO quando eu } \\
\text { escolho um estabelecimento hoteleiro. }\end{array}$ & \multirow{4}{*}{ (DAVIS, 1989) } \\
\hline & AT2 & $\begin{array}{l}\text { É sensato usar CVO quando eu } \\
\text { escolho um estabelecimento hoteleiro. }\end{array}$ & \\
\hline & AT3 & Eu gosto da ideia de usar CVO quando & \\
\hline & & $\begin{array}{l}\text { eu escolho um estabelecimento } \\
\text { hoteleiro. }\end{array}$ & \\
\hline \multirow{5}{*}{$\begin{array}{l}\text { Intenção } \\
\text { Comportamental }\end{array}$} & IN1 & Eu pretendo usar CVO da próxima que & \multirow{5}{*}{ (DAVIS, 1989) } \\
\hline & & vez eu escolher um estabelecimento & \\
\hline & & hoteleiro. & \\
\hline & IN2 & $\begin{array}{l}\text { Eu pretendo usar CVO sempre que eu } \\
\text { precisar escolher um estabelecimento } \\
\text { hoteleiro. }\end{array}$ & \\
\hline & IN3 & $\begin{array}{l}\text { Eu planejo usar CVO sempre que eu } \\
\text { escolher um estabelecimento hoteleiro. }\end{array}$ & \\
\hline \multirow{4}{*}{ Utilidade percebida } & UT1 & Usar CVO torna mais fácil para eu & \multirow{4}{*}{ (DAVIS, 1989) } \\
\hline & UT2 & $\begin{array}{l}\text { escolher um estabelecimento hoteleiro. } \\
\text { Usar CVO melhora minha capacidade } \\
\text { de escolher um estabelecimento } \\
\text { hoteleiro. }\end{array}$ & \\
\hline & UT3 & $\begin{array}{l}\text { Usar CVO permite-me escolher um } \\
\text { estabelecimento } \\
\text { rapidamente. }\end{array}$ & \\
\hline & UT4 & $\begin{array}{l}\text { Acho CVO úteis quando escolho um } \\
\text { estabelecimento hoteleiro. }\end{array}$ & \\
\hline \multirow{4}{*}{ Prazer percebido } & MO1 & Usar $\quad$ CVO quando escolho um & \multirow{4}{*}{$\begin{array}{c}\text { (DAVIS; } \\
\text { BAGOZZI; } \\
\text { WARSHAW, } \\
\text { 1992) }\end{array}$} \\
\hline & & estabelecimento hoteleiro é agradável. & \\
\hline & MO2 & $\begin{array}{l}\text { Usar CVO quando escolho um } \\
\text { estabelecimento hoteleiro é prazeroso. }\end{array}$ & \\
\hline & MO3 & $\begin{array}{l}\text { Eu me divirto usando CVO quando } \\
\text { escolho um estabelecimento hoteleiro. }\end{array}$ & \\
\hline \multirow{4}{*}{ Facilidade percebida } & FA1 & Aprender a usar CVO para escolher & \multirow{4}{*}{ (DAVIS, 1989) } \\
\hline & & $\begin{array}{l}\text { um estabelecimento hoteleiro é fácil } \\
\text { para mim. }\end{array}$ & \\
\hline & FA2 & $\begin{array}{l}\text { É fácil de usar CVO para encontrar a } \\
\text { informação que preciso ao escolher } \\
\text { um estabelecimento hoteleiro. }\end{array}$ & \\
\hline & FA3 & $\begin{array}{l}\text { Os CVO refletem meus interesses } \\
\text { quando eu escolho um } \\
\text { estabelecimento hoteleiro. }\end{array}$ & \\
\hline
\end{tabular}

Fonte: SILVA (2015). 


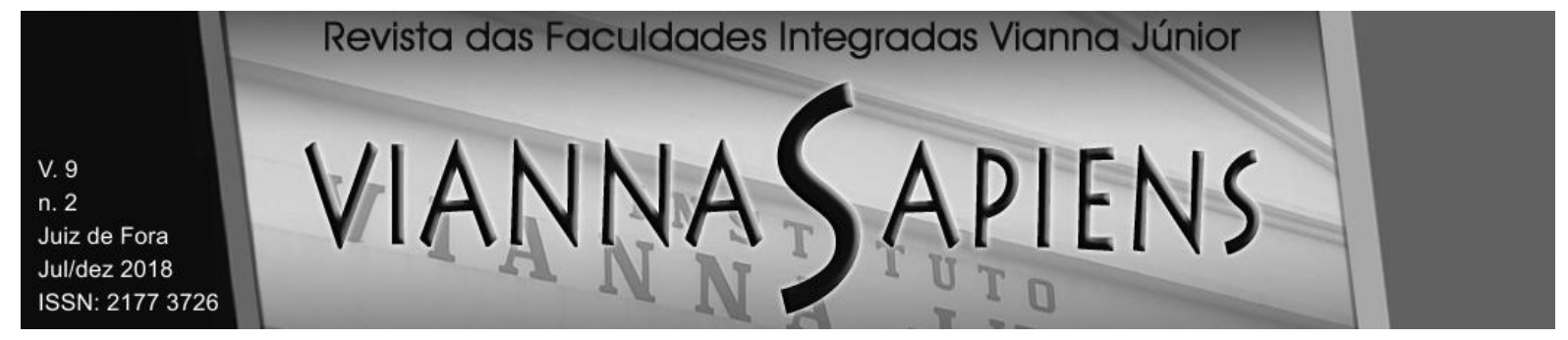

\subsection{Tratamento dos dados}

No presente trabalho, foi utilizado o software WarpPLS, versão 5.0, para tratar os dados por meio de modelagem de equações estruturais (MEE), com base em mínimos quadrados parciais (MQP), cuja escolha ocorreu em razão da complexidade do modelo, ao tamanho da amostra e ao desconhecimento da normalidade das variáveis.

\subsection{Hipótese Testadas}

Em função do modelo construído no referencial teórico e sintetizado na Figura 2, forma testadas as hipóteses descritas no Quadro 2.

\section{Quadro 2 - Hipóteses Testadas}

\section{Hipótese}

H1: Utilidade percebida de uso de CVO influencia positivamente a atitude em utilizá-lo na escolha de um meio de hospedagem.

H2: Utilidade percebida de uso de CVO influencia positivamente a intenção de utilizá-lo na escolha de um meio de hospedagem.

H3: Facilidade percebida no uso de CVO influencia positivamente utilidade percebida na escolha de um meio de hospedagem.

H4: Facilidade percebida no uso de CVO influencia positivamente atitude em utilizá-lo na escola de um meio de hospedagem.

H5: Atitude em usar CVO influencia positivamente a intenção de utilizá-lo na escolha de um meio de hospedagem.

H6: Prazer percebido influencia positivamente a facilidade percebida de usar CVO na escolha de um meio de hospedagem.

H7: Prazer percebido influencia positivamente a atitude de usar CVO na escolha de um meio de hospedagem.

H8: Prazer percebido influencia positivamente a intenção de usar CVO na escolha de um meio de hospedagem.

Fonte: Elaboração própria. 


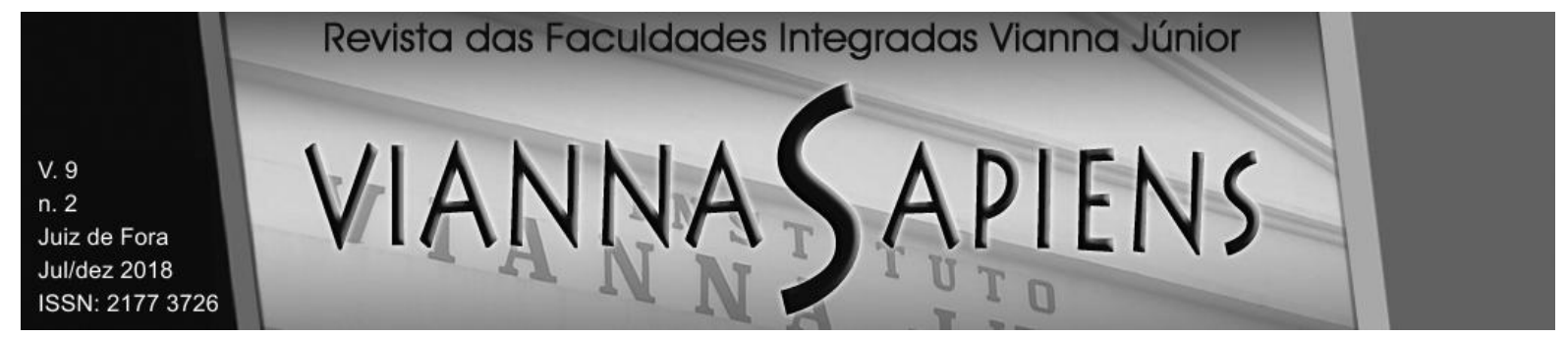

\section{RESULTADOS}

A análise de resultados desta pesquisa foi realizada em duas etapas. A primeira etapa foi responsável por avaliar o modelo de mensuração. A segunda etapa teve o objetivo de avaliar o modelo estrutural. Trata-se do procedimento mais indicado quando os dados são tratados por meio de MEE, com MQP (HENSELER; RINGLE; SINKOVICS, 2009; HAIR et al., 2014a).

O modelo de mensuração, também referenciado como modelo externo, exibe as relações entre as variáveis latentes e as variáveis observadas. A sua avaliação, em modelos reflexivos, ocorre por meio da análise de confiabilidade composta (CC), de variância média extraída (VME), e de cargas cruzadas, sendo, complementarmente, utilizado o critério de Fornell e Larcker (1981) (HENSELER; RINGLE; SINKOVICS, 2009; RINGLE; SILVA; BIDO, 2014; HAIR et al., 2014a; HAIR et al., 2014b).

A análise de confiabilidade composta (CC) é responsável por mensurar a confiabilidade da consistência interna dos indicadores. Ela avalia com precisão adequada se a amostra não tem vieses e se os indicadores são capazes de extrair informações confiáveis. Entende-se que valores compreendidos entre 0,70 a 0,90 são satisfatórios (HAIR et al., 2014a; HAIR et al., 2014b; RINGLE; SILVA; BIDO, 2014).

Apesar do alfa de Cronbach não ser um indicador indispensável em MEE, com MQP, ele foi analisado no presente trabalho. Espera-se que o alfa de Cronbach esteja acima de 0,70, não obstante sejam aceitáveis valores superiores a 0,60, quando se trata de pesquisa em Ciências Sociais (HAIR et al., 2014b).

No que se refere à análise da variância média extraída (VME), o objetivo se concentra na verificação da validade convergente, que pode ser explicada pela extensão em que uma medida se correlaciona de forma positiva com medidas alternativas do mesmo construto. O valor da VME de cada variável latente precisa ser igual ou superior a 0,50 , pois isso demonstra que, em média, o construto explica 


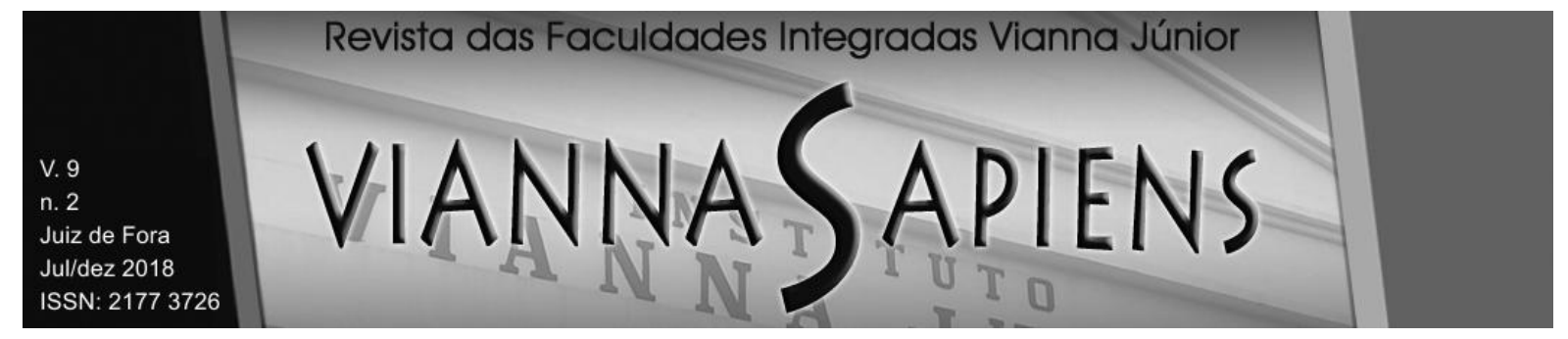

mais do que a média de variância de seus indicadores (HAIR et al., 2014a; HAIR et al., 2014b; HENSELER; HUBONA; RAY, 2016).

No presente estudo, conforme podem ser visualizados na Tabela 1, os valores encontrados na análise de CC e de VME são adequados. O alpha de Cronbach da variável latente Intenção (IT) apresentou valor maior que 0,70.

Tabela 1 - Alpha de Cronbach, Confiabilidade Composta (CC) e Variância Média Extraída (VME)

\begin{tabular}{lccr}
\hline Variável Latente & Alpha de Cronbach & CC & VME \\
\hline Atitude (AT) & 0,893 & 0,934 & 0,825 \\
Facilidade (FA) & 0,829 & 0,887 & 0,665 \\
Intenção (IT) & 0,817 & 0,891 & 0,733 \\
Prazer (MO) & 0,799 & 0,882 & 0,714 \\
Utilidade (UT) & 0,764 & 0,851 & 0,591 \\
\hline
\end{tabular}

Fonte: Elaboração própria.

No que diz respeito à avaliação das cargas cruzadas ou ao critério de Fornell e Larcker (1981), o intuito é analisar a validade discriminante dos construtos, ou seja, o quanto eles são independentes um dos outros (HAIR et al., 2014b).

O exame das cargas cruzadas tem o objetivo de analisar se os indicadores possuem cargas fatoriais mais elevadas em seus respectivos construtos. $O$ critério de Fornell e Larcker (1981) é uma abordagem mais conservadora para avaliar a validade discriminante, pois verifica se a raiz quadrada de cada VME é superior à sua maior correlação com qualquer outra variável latente do modelo (HAIR et al., 2014b; HENSELER; HUBONA; RAY, 2016).

Neste trabalho, os resultados obtidos atendem aos dois critérios mencionados para avaliar a validade discriminante dos construtos, conforme pode ser observado nas Tabelas 2 e 3. 


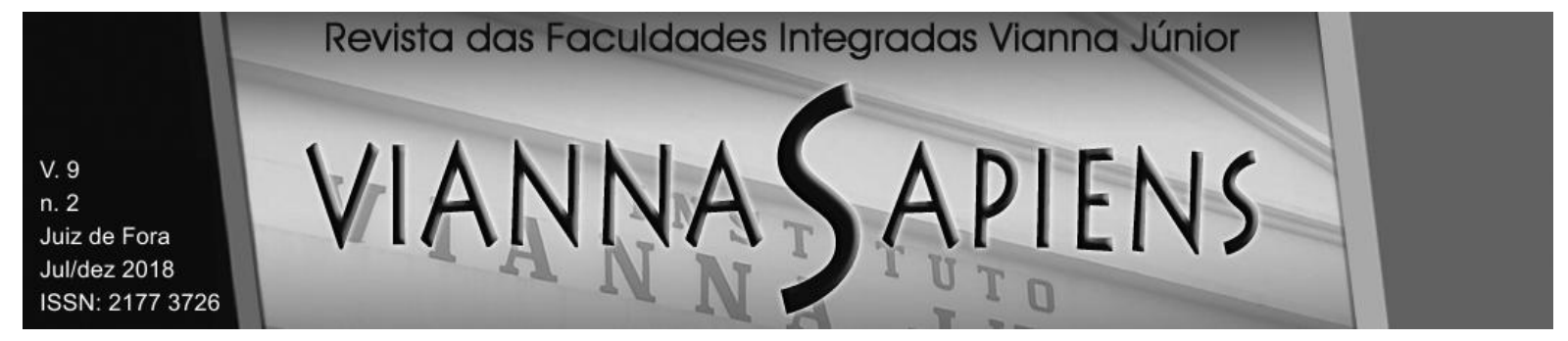

Tabela 2 - Avaliação das Cargas Cruzadas

\begin{tabular}{llllll}
\hline & $\mathbf{U T}$ & FA & AT & MO & IT \\
\hline UT1 & $\mathbf{( 0 . 7 9 2 )}$ & -0.032 & 0.087 & -0.086 & -0.127 \\
UT2 & $\mathbf{( 0 . 8 2 3 )}$ & 0.013 & 0.290 & -0.121 & -0.041 \\
UT3 & $\mathbf{( 0 . 6 0 9 )}$ & 0.015 & -0.763 & 0.344 & 0.362 \\
UT4 & $\mathbf{( 0 . 8 3 0 )}$ & 0.007 & 0.189 & -0.050 & -0.103 \\
FA1 & -0.105 & $\mathbf{( 0 . 8 1 8 )}$ & 0.171 & 0.250 & -0.128 \\
\hline FA2 & -0.066 & $\mathbf{( 0 . 8 5 9 )}$ & 0.257 & -0.058 & -0.127 \\
FA3 & -0.130 & $\mathbf{( 0 . 8 7 0 )}$ & -0.025 & -0.086 & -0.025 \\
FA4 & 0.364 & $\mathbf{( 0 . 7 0 4 )}$ & -0.481 & -0.115 & 0.334 \\
AT1 & -0.035 & -0.064 & $\mathbf{( 0 . 9 3 3 )}$ & 0.000 & -0.080 \\
AT2 & 0.091 & -0.082 & $\mathbf{( 0 . 9 1 5 )}$ & -0.055 & -0.049 \\
AT3 & -0.058 & 0.154 & $\mathbf{( 0 . 8 7 5 )}$ & 0.058 & 0.137 \\
M01 & -0.014 & 0.073 & 0.181 & $\mathbf{( 0 . 8 2 3 )}$ & -0.040 \\
MO2 & -0.075 & -0.013 & -0.168 & $\mathbf{( 0 . 8 9 6 )}$ & 0.182 \\
MO3 & 0.096 & -0.059 & 0.002 & $\mathbf{( 0 . 8 1 4 )}$ & -0.161 \\
IT1 & -0.109 & -0.073 & 0.133 & -0.055 & $\mathbf{( 0 . 8 2 2 )}$ \\
IT2 & 0.065 & -0.062 & 0.012 & 0.076 & $\mathbf{( 0 . 8 7 9 )}$ \\
IT3 & 0.038 & 0.132 & -0.138 & -0.024 & $\mathbf{( 0 . 8 6 6 )}$ \\
\hline
\end{tabular}

Fonte: Elaboração própria.

Tabela 3 - Critério de Fornell-Larcker

\begin{tabular}{lccccc}
\hline & UT & FA & AT & MO & IT \\
\hline UT & $\mathbf{( 0 . 7 6 9 )}$ & & & & \\
FA & 0.594 & $\mathbf{( 0 . 8 1 5 )}$ & & & \\
AT & 0.639 & 0.609 & $\mathbf{( 0 . 9 0 8 )}$ & & \\
MO & 0.425 & 0.499 & 0.380 & $\mathbf{( 0 . 8 4 5 )}$ & \\
IT & 0.623 & 0.488 & 0.731 & 0.448 & $\mathbf{( 0 . 8 5 6 )}$ \\
\hline
\end{tabular}

Fonte: Elaboração própria.

Antes de iniciar a análise do modelo estrutural, é recomendável verificar o fator de inflação de variância (VIF) para identificar possíveis problemas de multicolinearidade entre as variáveis latentes. Construtos com valores de VIF abaixo de 5 são satisfatórios, possibilitando rejeitar a hipótese de multicolinearidade entre os construtos do modelo (HAIR et al., 2014b). Conforme pode ser observado na tabela 4, não há problemas de multicolinearidade entre as variáveis latentes. 




Tabela 4 - Fator de Inflação de Variância (VIF)

\begin{tabular}{cc}
\hline Variável Latente & VIF \\
\hline Atitude & 2.754 \\
Facilidade & 1.995 \\
Intenção & 2.489 \\
Prazer & 1.456 \\
Utilidade & 2.091 \\
\hline
\end{tabular}

Fonte: Elaboração própria.

O modelo estrutural desta pesquisa foi analisado por meio da verificação do coeficiente de determinação de Pearson $\left(R^{2}\right)$, da avaliação da significância estatística dos coeficientes de caminho $(\beta)$, da avaliação da relevância preditiva $\left(Q^{2}\right)$ e da avaliação do tamanho do efeito $\left(\mathrm{f}^{2}\right)$, por serem as medidas mais adequadas para avaliar o modelo interno em MEE, com MQP (HAIR et al., 2014b).

O coeficiente de determinação de Pearson $\left(R^{2}\right)$ é a medida mais utilizada para avaliar o modelo estrutural em MEE, com MQP. Trata-se de uma medida preditiva do modelo. $O \mathrm{R}^{2}$ analisa os efeitos das variáveis latentes exógenas sobre as variáveis latentes endógenas. Os valores de $R^{2}$ variam de 0 a 1 . Quanto mais os valores se aproximam de 1, maior é a exatidão preditiva (HAIR et al., 2014b).

Como é possível verificar na Figura 3, a Intenção (IT), principal variável latente endógena do modelo, apresentou valor $R^{2}$ de 0,61 . 

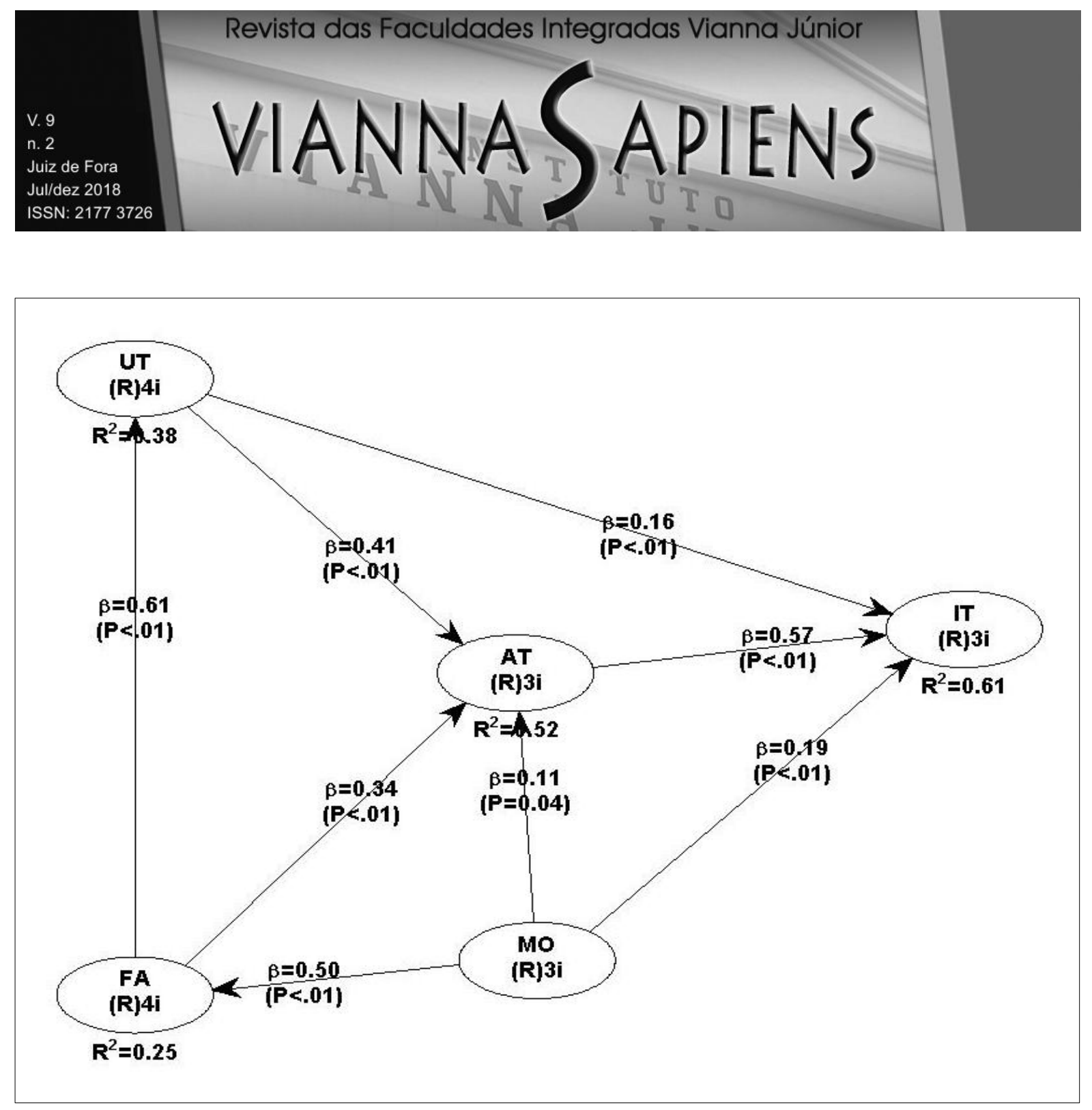

Figura 3 - Diagrama de Caminho

Fonte: Elaboração própria

No que se refere à avaliação da significância estatística dos coeficientes de caminho $(\beta)$, é importante ressaltar que o $\beta$ representa as relações hipotéticas entre os construtos, que só podem ser aceitas se houver significância estatística. Os resultados dos coeficientes sempre estão contidos entre -1 e 1, variando de uma relação negativa a positiva, sendo que quanto mais próximo os valores estiverem dos extremos, mais fortes serão as relações entre os construtos (HAIR et al., 2014b).

As relações entre os construtos do modelo utilizados neste trabalho tiveram significância estatística, conforme demonstrado na Figura 3 e na Tabela 5.

Sobre a avaliação da relevância preditiva $\left(\mathrm{Q}^{2}\right)$, também conhecido como indicador de Stone-Geisser, cabe mencionar que o objetivo é analisar quanto o 




modelo se aproxima do que se espera dele. Valores de 0,$02 ; 0,15$; e 0,35 indicam que um construto exógeno tem relevância preditiva pequena, média ou grande, respectivamente (RINGLE; SILVA; BIDO, 2014; HAIR et al., 2014b).

Tabela 5 - Coeficientes de caminho $(\beta)$ e significância estatística (p)

\begin{tabular}{lcc}
\hline Caminho & B & $\mathbf{P}$ \\
\hline UT $\rightarrow$ IT & 0,16 & $<0,01$ \\
UT $\rightarrow$ AT & 0,41 & $<0,01$ \\
FA $\rightarrow$ UT & 0,61 & $<0,01$ \\
FA $\rightarrow$ AT & 0,34 & $<0,01$ \\
AT $\rightarrow$ IT & 0,57 & $<0,01$ \\
MO $\rightarrow$ AT & 0,11 & 0,04 \\
MO $\rightarrow$ FA & 0,50 & $<0,01$ \\
MO $\rightarrow$ IT & 0,19 & $<0,01$ \\
\hline
\end{tabular}

Fonte: Elaboração própria.

Os resultados encontrados neste trabalho indicaram que a principal variável endógena do modelo, Intenção, teve o $Q^{2}$ de 0,61 . As outras três variáveis latentes do modelo, Utilidade, Facilidade e Atitude, apresentaram valores $\mathrm{Q}^{2}$ de 0,38, 0,25 e 0,52 respectivamente.

Por último, no que se refere à avaliação do tamanho do efeito $\left(\mathfrak{f}^{2}\right)$, também conhecido como indicador de Cohen (1988), é importante ressaltar que os valores 0,02, 0,15 e 0,35, representam efeitos pequeno, médio e grande da variável latente exógena, respectivamente (HAIR et al., 2014b).

Os resultados encontrados no presente trabalho podem ser observados na tabela 6. 


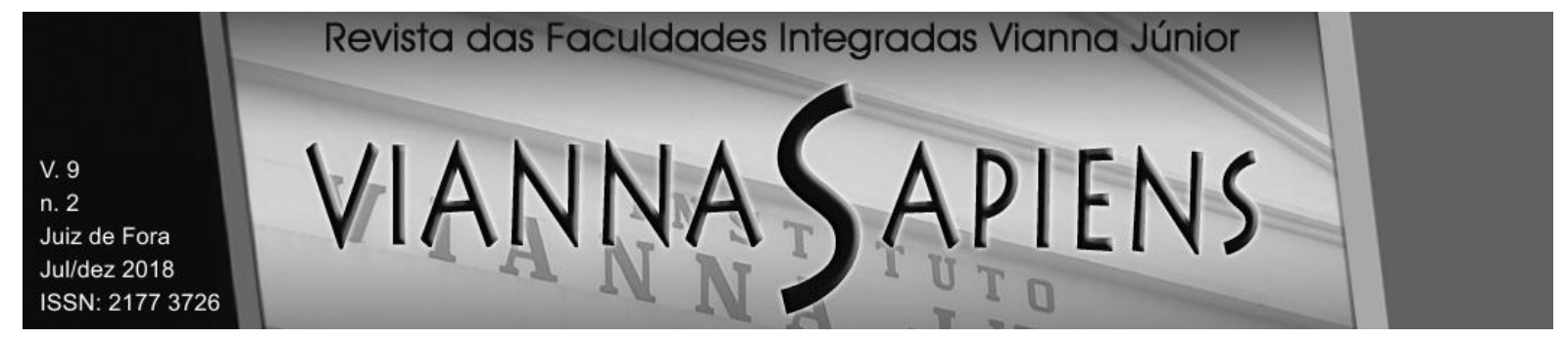

Tabela 6 - Tamanho do efeito $\left(f^{2}\right)$

\begin{tabular}{cc}
\hline Caminho & $\mathbf{f}^{\mathbf{2}}$ \\
\hline UT $\rightarrow$ AT & 0,263 \\
UT $\rightarrow$ IT & 0,100 \\
FA $\rightarrow$ UT & 0,375 \\
FA $\rightarrow$ AT & 0,207 \\
AT $\rightarrow$ IT & 0,422 \\
MO $\rightarrow$ FA & 0,252 \\
MO $\rightarrow$ AT & 0,045 \\
MO $\rightarrow$ IT & 0,087 \\
\hline
\end{tabular}

Fonte: Elaboração própria.

O Quadro 3 mostra que todas as hipóteses do modelo foram aceitas.

\section{Quadro 3 - Confirmação ou rejeição das hipóteses fundamentais do modelo hipotético de intenção}

\begin{tabular}{lc}
\hline \multicolumn{1}{c}{ Hipótese } & Resultado obtido \\
\hline $\begin{array}{l}\text { H1:Utilidade percebida de uso de CVO influencia positivamente a } \\
\text { atitude em utilizá-lo na escolha de um meio de hospedagem. }\end{array}$ & Confirma H1 \\
$\begin{array}{l}\text { H2: Utilidade percebida de uso de CVO influencia positivamente a } \\
\text { intenção de utilizá-lo na escolha de um meio de hospedagem. }\end{array}$ & Confirma H2 \\
$\begin{array}{l}\text { H3: Facilidade percebida no uso de CVO influencia positivamente } \\
\text { utilidade percebida na escolha de um meio de hospedagem. }\end{array}$ & Confirma H3 \\
H4: Facilidade percebida no uso de CVO influencia positivamente & Confirma H4 \\
$\begin{array}{l}\text { atitude em utilizá-lo na escola de um meio de hospedagem. } \\
\text { H5: Atitude em usar CVO influencia positivamente a intenção de } \\
\text { utilizá-lo na escolha de um meio de hospedagem. }\end{array}$ & Confirma H5 \\
$\begin{array}{l}\text { H6: Prazer percebido influencia positivamente a facilidade percebida de } \\
\text { usar CVO na escolha de um meio de hospedagem. }\end{array}$ & Confirma H6 \\
$\begin{array}{l}\text { H7: Prazer percebido influencia positivamente a atitude de usar CVO na } \\
\text { escolha de um meio de hospedagem. }\end{array}$ & Confirma H7 \\
$\begin{array}{l}\text { H8: Prazer percebido influencia positivamente a intenção de usar CVO } \\
\text { na escolha de um meio de hospedagem. }\end{array}$ & Confirma H8 \\
Fonte: Elaboração própria. &
\end{tabular}




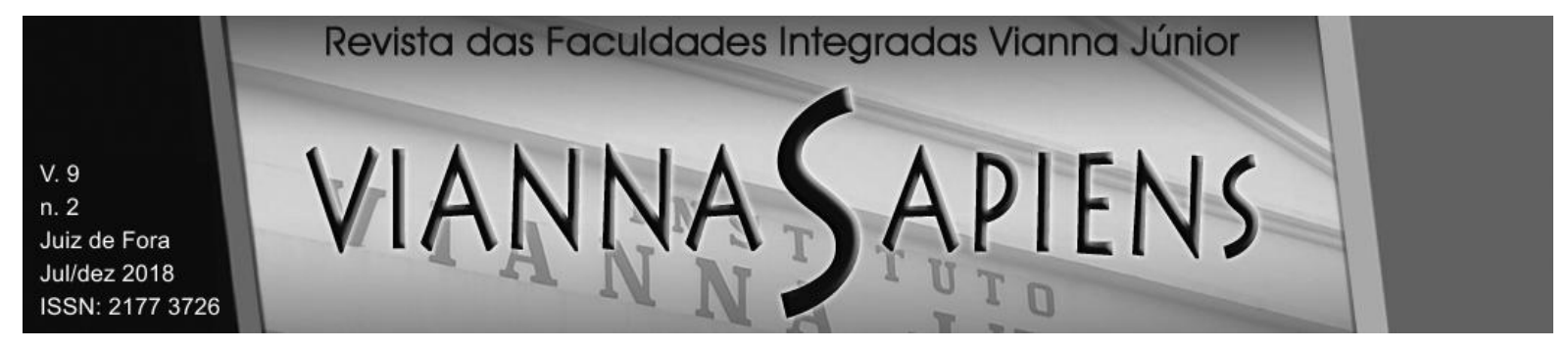

\section{CONCLUSÃO}

Este estudo respondeu positivamente ao seu objetivo principal: há um nexo causal entre os construtos exógenos (atitude percebida; utilidade percebida; prazer percebido; e facilidade percebida) e o endógeno (intenção de uso), ou seja, os CVO influenciam a escolha de meio de hospedagem por viajantes que estão em fase de planejamento ou de efetivação de seus roteiros de viagem.

Convém notar que o modelo teórico de Silva e Mendes Filho (2014) exibe evidências de solidez, muito embora não possamos validá-lo, haja vista que a MEE utilizada no estudo não possibilita o teste de teoria. Para tanto, seria preciso realizar outro estudo, tratando os dados do modelo com modelagem de equações estruturais, fundamentada em matriz de covariância. Todavia, a natureza exploratória do presente trabalho atesta que o modelo de Silva e Mendes Filho (2014) apresenta potencial para dar continuidade a pesquisas na esfera de CVO.

Observou-se que os resultados apontam a existência de influência direta e positiva das variáveis: Utilidade, Facilidade, Prazer e Atitude na Intenção do Consumidor, principal variável latente explicativa do modelo, tendo em conta que Atitude foi a variável latente que mais influenciou IT, a intenção de utilizar CVO.

É importante ressaltar que, indo ao encontro de resultados empíricos de diversos autores (CASTAÑEDA et al., 2007; HUH; KIM; LAW, 2009; AYEH; AU; LAW, 2013; SILVA; MENDES FILHO, 2014; MENDES FILHO; JORGE; SENA JÚNIOR, 2016; LIMA JÚNIOR et al., 2016; LAI, 2017), os resultados identificaram que a facilidade percebida e a utilidade percebida influenciam significativamente a atitude, ratificando os pilares dessa última variável latente, consubstanciados nos seguintes itens do questionário: é uma boa ideia usar CVO quando eu escolho um estabelecimento hoteleiro; é sensato usar CVO quando eu escolho um estabelecimento hoteleiro; eu gosto da ideia de usar CVO quando eu escolho um estabelecimento hoteleiro.

Com efeito, a atitude é fundamental, uma vez que ela é a variável latente que 


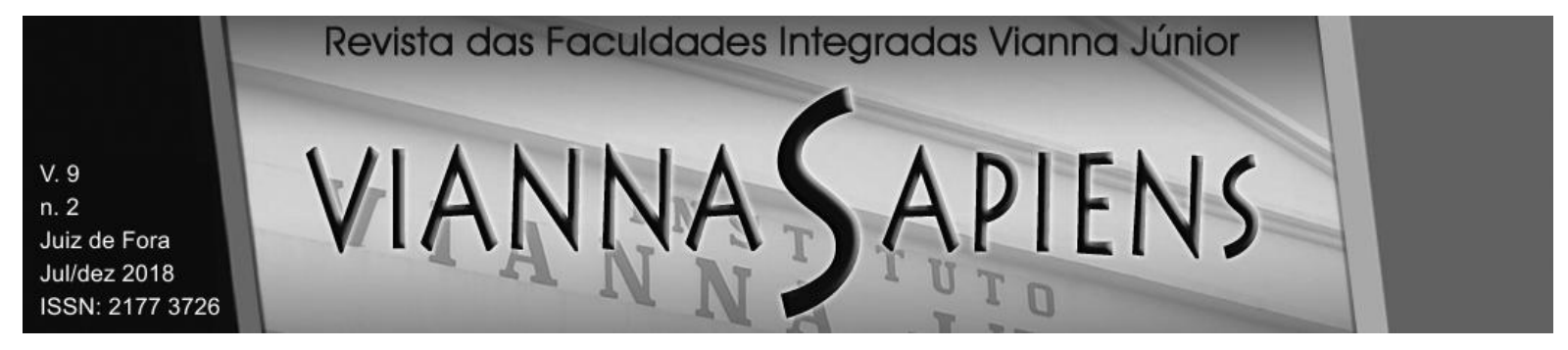

exerce maior impacto direto sobre a intenção de se utilizar CVO.

É importante mencionar que na pesquisa de Silva e Mendes Filho (2014), as hipóteses H4 (Facilidade percebida no uso do CVO influencia positivamente atitude em utilizá-lo na escola de um meio de hospedagem), H7 (Prazer percebido influencia positivamente a atitude de usar o CVO na escolha de um meio de hospedagem) e H8 (Prazer percebido influencia positivamente a intenção de usar o CVO na escolha de um meio de hospedagem) foram rejeitadas.

Entretanto, os resultados encontrados no presente estudo suportam as oito hipóteses que foram utilizadas, sinalizando talvez melhoria na estruturação dos sites de viagem, facilitando a navegação e a busca. Na realidade, desde a publicação do estudo de Silva e Mendes Filho (2014), o avanço dos sites de busca foi muito grande, notadamente aqueles relativos a viagens. Qualquer que seja o destino procurado, a busca por comentário de viajantes mostra-se imprescindível, assim como a opinião dos turistas quanto à qualidade de hotéis, classificados por preço, localização e qualidade do serviço.

Os comentários dos turistas, assim como as demais informações disponíveis nos sites de viagem, possibilitam a adequação do nível de qualidade percebida do hotel, os preços praticados e localização, entre outras variáveis, às exigências do turista potencial, as quais são partes constituintes de seu perfil.

Para a academia, este estudo contribui para aumentar a compreensão teórica do assunto, extraindo insights que permitem ampliar o entendimento da intenção da utilização de CVO na escolha de meio de hospedagem.

Este estudo apresenta algumas limitações. Inicialmente, o estudo foi feito a partir de amostras por conveniência. Esse tipo de amostra não possibilita que os resultados sejam generalizados para população. Sugere-se a utilização de amostras aleatórias maiores para refinar ainda mais o instrumento de coleta de dados e o próprio modelo.

Recomenda-se também o emprego de modelagem de equações estruturais, fundamentada em matriz de covariância, para validar o modelo teórico. É possível 


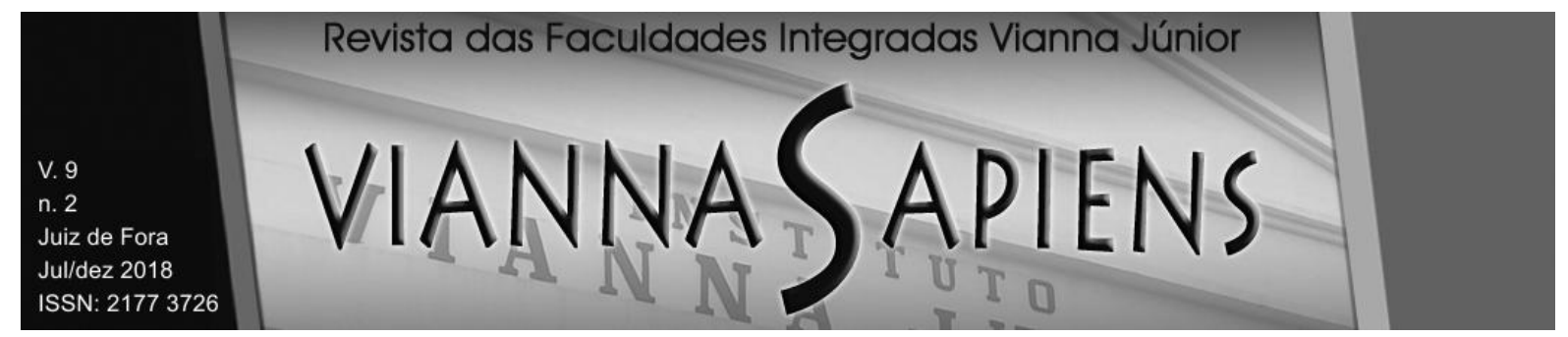

passar do estudo exploratório para o teste teórico. O aludido tipo de modelagem de equações estruturais exige amostra grande, preferencialmente aleatória, e distribuição normal multivariada, para gerar resultados consistentes, permitindo que a solidez do modelo seja testada.

Ademais, este estudo baseia-se em fotografia de determinado momento no tempo, caracterizando o seu aspecto transversal. Sugere-se o desenvolvimento de estudo longitudinal, para que surjam outros insights importantes sobre a relevância dos comentários de turistas em sites de viagem. Em um estudo longitudinal, o modelo de pesquisa abrangeria diferentes períodos e as comparações seriam mais ricas, proporcionando maior compreensão sobre o uso de CVO na escolha de meio de hospedagem.

\section{REFERÊNCIAS}

AJZEN, I. Attitude structure and behavior. In: PRATKANIS, A.; BRECKLER, S.; GREENWALD, A. (Org.), Attitude structure and function. Hillsdale, NJ: Laurence Erlbaum Associates, 1989. p. 241-274.

AYEH, J. K.; AU, N.; LAW, R. Predicting the intention to use consumer-generated media for travel planning. Tourism Management, v. 35, n. 1, p. 132-143, 2013.

CASALÓ, L. V., FLAVIÁN, C., GUINALÍU, M. Understanding the intention to follow the advice obtained in an on-line travel community. Computers in Human Behavior, v. 27, n. 2, p. 622-633, 2011.

CASTAÑEDA, J. A.; FRÍAS, D. M.; MUNOZ-LEIVA, F.; RODRIGUEZ, M.A. Extrinsic and intrinsic motivation in the use of Internet as a tourist information source.

International Journal of Internet Marketing \& Advertising, v. 4, n. 1, p. 37-52, 2007. 


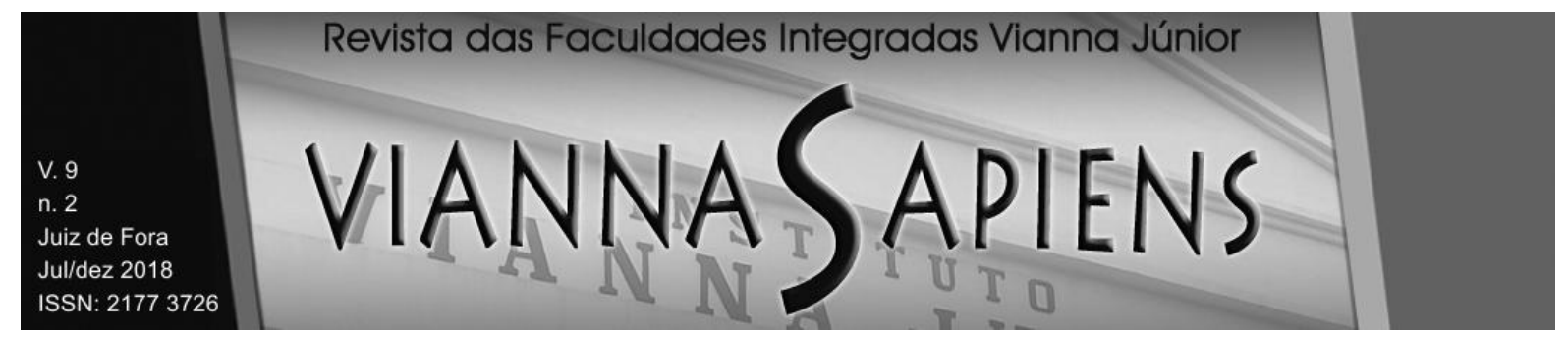

COHEN, J. Statistical power analysis for the behavioral sciences. Hillsdale, NJ: Lawrence Earlbaum Associates, 1988.

CORTEZ, M. C. A., MONDO, T.S. Comentários On-line: Formação de Expectativa e Decisão de Compra de Consumidores Hoteleiros. Rosa dos Ventos Turismo e Hospitalidade, v.10, n. 1, p. 119-135, 2018.

DAVIS, F. D. Perceived usefulness, perceived ease of use, and user acceptance of information technology. MIS Quarterly, v. 13, n.3, p. 319-339, 1989.

DAVIS, F. D.; BAGOZZI, R. P.; WARSHAW, P. R. Extrinsic and intrinsic motivation to use computers in the workplace. Journal of Applied Social Psychology, v. 22, n. 1, p. 1111-1132, 1992.

FILIERI, R.; ALGUEZAUI, S.; MCLEAY, F. Why do travelers trust TripAdvisor? Antecedents of trust towards consumer-generated media and its influence on recommendation adoption and word of mouth. Tourism Management, v. 51, 174185,2015

FORNELL, C.; LARCKER, D. F. Evaluating structural equation models with unobservable variables and measurement error. Journal of Marketing Research, v. 18, n.1, p. 39-50, 1981.

GOUVÊA, M. A.; SÁ, L. F. J.; MANTOVANI, D. M. N. Aspectos discriminantes entre usuários e não usuários da internet banda larga. Revista de Administração e Inovação, v. 9, n. 3, p. 195-212, 2012.

HAIR, J.; SARSTEDT, M.; HOPKINS, L.; KUPPELWIESER, V. Partial least squares structural equation modeling (PLS-SEM): an emerging tool in business research. European Business Review, v. 26, n. 2, p.106-121, 2014a.

HAIR, J.; HULT, G.; RINGLE, C.; SARSTEDT, M. A Primer on Partial Least Squares Structural Equation Modeling (PLS-SEM). Los Angeles: SAGE, 2014b. 


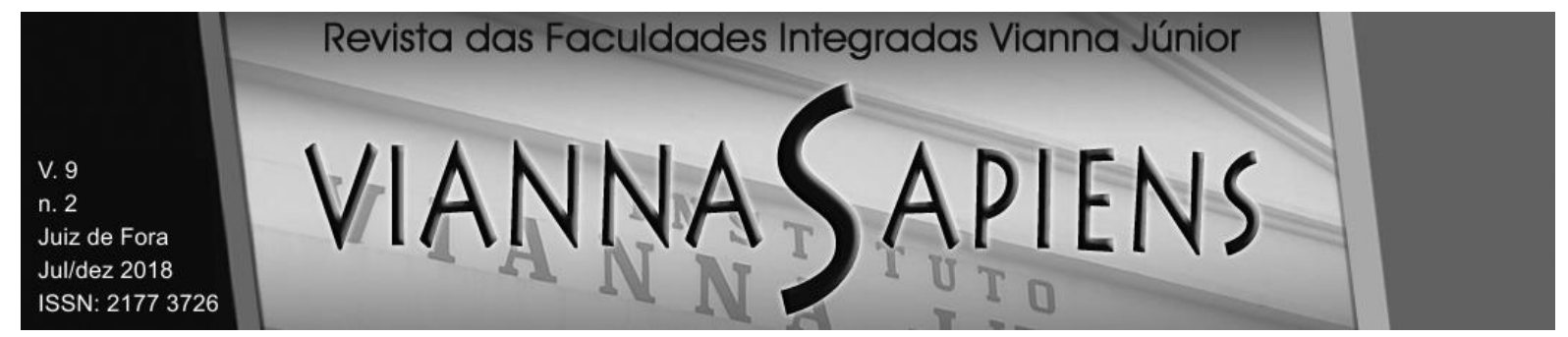

HENNIG-THUARU, T.; GWINNER, K. P.; WALSH, G.; GREMLER, D. D. Electronic word-of-mouth via consumer opinion platforms: What motivates consumers to articulate themselves on the Internet? Journal of Interactive Marketing, v. 18, v.1, p. 38-52, 2004.

HENSELER, J.; RINGLE, C. M.; SINKOVICS, R. R. The use of partial least squares path modeling in international marketing. Advances in International Marketing, $\mathrm{v}$. 20, p. 277-319, 2009.

HENSELER, J.; HUBONA, G.; RAY, P. A. Using PLS path modeling in new technology research: updated guidelines. Industrial Management \& Data Systems, v. 116, n. 1, p. 2-20, 2016.

HUH, H. J.; KIM, T.; LAW, R. A comparison of competing theoretical models for understanding acceptance behavior of information systems in upscale hotels.

International Journal of Hospitality Management, v. 28 n. 1, p. 717-724, 2009.

LAI, P. The Literature Review of Technology Adoption Models and Theories for the Novelty Technology. JISTEM - Journal of Information Systems and Technology Management, v. 14, n. 1, p. 21-38, 2017.

LIMA JÚNIOR, J. A.; MENDES FILHO, L.; SILVA, G. L.; SOUZA, J. Comentários de Viagem na Internet na Escolha de um Destino Turístico: Um Estudo Baseado nas Teorias do Comportamento Planejado e Aceitação Tecnológica. Turismo: Visão e Ação, v. 18, n. 2, p. 300-326, 2016.

MAURI, A. G.; MINAZZI, R. Web reviews influence on expectations and purchasing intentions of hotel potential customers. International Journal of Hospitality

Management, v. 34, p. 99-107, 2013.

MENDES FILHO, L.; JORGE, V. A.; SENA JÚNIOR, O. B. Percepção do uso de sites de compras coletivas ao adquirir cupons de serviços turísticos. Revista Brasileira de Pesquisa em Turismo, v. 10, n. 3, p. 574-593, 2016. 


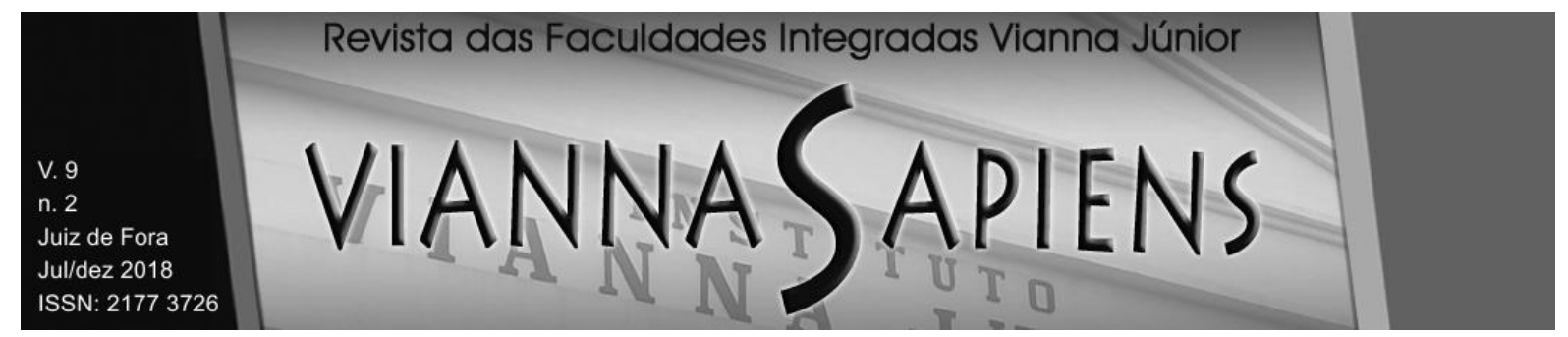

MOROSAN, C.; BOWEN, J. Analytic perspectives on on-line purchasing in hotels: a review of literature and research directions. International Journal of Contemporary Hospitality Management, v. 30, n.6, 2017.

RINGLE, C. M.; SILVA, D.; BIDO, D. Modelagem de equações estruturais com utilização do SmartPLS. Revista Brasileira de Marketing - ReMark, v.13, n.2, 2014. Edição especial.

RYAN, R. M.; DECI, E. L. On happiness and human potentials: a review of research on hedonic and eudaimonic well-being. Annual Review of Psychology, v. 52, p. 141-166, 2001.

SANTOS, S.E.M.; CHAVES, M.S.; PEDRON, C.D. An Analysis of Open-Ended Online Reviews about Bed and Breakfast and Inns in Portugal. Revista Brasileira de Pesquisa em Turismo, v. 8 n.1, p. 99-119, 2014.

SCHUCKERT, M.; XIANWEI, L.; LAW, R. Hospitality and Tourism On-line Reviews: Recent Trends and Future Directions. Journal of Travel \& Tourism Marketing, v. 32. p. 608-621, 2015.

SILVA, M. M. Antecedentes da intenção de uso de comentários de viagem online na escolha de um meio de hospedagem. Natal: UFRN, 2015.

SILVA, M. M.; MENDES FILHO, L. Intenção de uso de comentários de viagem online na escolha de um meio de hospedagem: Fatores influenciadores. Revista Brasileira de Pesquisa em Turismo, v. 8, n. 3, p. 419-434, 2014.

SPARKS, B. A.; PERKINS, H. E.; BUCKLEY, R. Online travel reviews as persuasive communication: The effects of content type, source, and certification logos on consumer behavior. Tourism Management, v. 39, p. 1-9, 2013.

YE, Q.; LAW, R; GU, B. The Impact of Online User Reviews on Hotel Room Sales. International. Journal of Hospitality Management, n. 28, p. 180-182, 2009. 


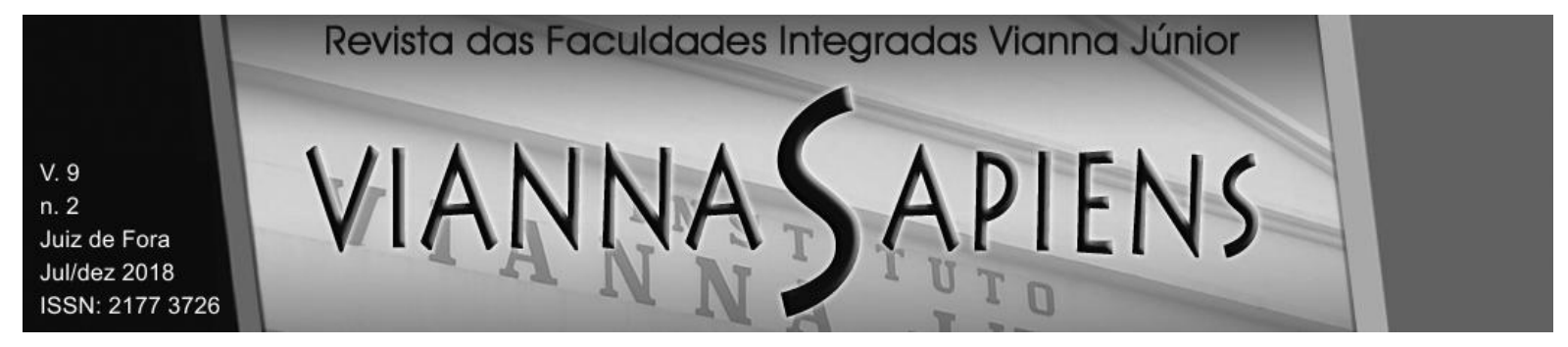

Recebido em 29/06/2018

Publicado em 21/12/2018 